\title{
CODATA - Comunidade Colaborativa de Dados
}

\author{
Andreia Machado Oliveira ${ }^{1,2}$, Fabiane Urquhart Duarte ${ }^{2}$, Gabriel Oliveira \\ Kolton $^{1}$, Lissandra Boessio ${ }^{2}$, Mara Regina Radaelli ${ }^{2}$, Ricardo Radaelli Meira ${ }^{1}$, \\ Tatiana Palma Guerche ${ }^{1}$, Ícaro Raupp Henrique ${ }^{3}$ \\ ${ }^{1}$ LabInter/PPG em Artes Visuais - Centro de Artes e Letras \\ Universidade Federal de Santa Maria (RS) 97105-900 - Santa Maria - RS - Brasil \\ ${ }^{2}$ LabInter/PPG em Tecnologias Educacionais em Rede - Centro de Educação \\ Universidade Federal de Santa Maria (RS) 97105-900 - Santa Maria - RS - Brasil \\ ${ }^{3}$ Faculdade de Informática- PUCRS e Emp - POA - RS - Brasil \\ andreiaoliveira.bragmail.com, fabianeurquhart@yahoo.com.br, \\ gabriel kolton@hotmail.com, liboesio@gmail.com, maradaelli@gmail.com, \\ ricardoradaelli@gmail.com, tatiguerche@hotmail.com, budicaro@gmail.com
}

\begin{abstract}
The interactive app CODATA (Collaborative Data Community) for mobile devices with Android operating system, has been developmented by gpc.interArtec / CNPq in LabInter / UFSM. It proposes a data visualization in order to promote the creation of collaborative community data. In education, it focuses on online data distribution in an interdisciplinary interaction for Innovative High School, discussing pedagogically as new communication approaches can change social dynamics from the everyday micro-policies and their integration experiences by the distribution of data in a collaborative network online.
\end{abstract}

Resumo. O aplicativo interativo CODATA (Comunidade Colaborativa de Dados/Collaborative Data Community) para dispositivos móveis com sistema operacional Android, em desenvolvimento pelo gpc.interArtec/CNPq no LabInter/UFSM, propõe um modo de visualização de dados que promova a criação de comunidade colaborativas de dados. No âmbito educacional, focase sobre a distribuição de dados online em um viés de interação interdisciplinar para o Ensino Médio Inovador, problematizando pedagogicamente como novas abordagens comunicacionais podem alterar dinâmicas sociais a partir de micro-políticas do cotidiano e suas experiências de integração via a distribuição de dados em uma rede colaborativa online.

\section{Cenário de Uso}

O aplicativo interativo CODATA (Comunidade Colaborativa de Dados/Collaborative Data Community) em desenvolvimento pelo grupo de pesquisa e criação em Interatividade, Arte e Tecnologia do $\mathrm{CNPq}$ (interArtec/CNPq) no Laboratório Interdisciplinar Interativo na Universidade Federal de Santa Maria/Brasil (LabInter/UFSM), é destinado para dispositivos móveis com Sistema Operacional Android. Com tal aplicativo, investigamos um modo criativo e interativo de visualização de dados que propicie a construção de comunidade colaborativas de 
dados, bem como problematizamos como novas abordagens comunicacionais podem alterar dinâmicas sociais a partir de micro-políticas do cotidiano e suas experiências de integração. Observamos que o desenvolvimento constante de tecnologias audiovisuais em rede voltadas à construção de narrativas digitais e distribuição online se direciona à apropriação tecnológica e à inovação de novas linguagens comunicacionais.

Assim, a partir da constatação de um número cada vez maior de produção de dados audiovisuais educacionais, em especial no Ensino Médio Inovador, o aplicativo educacional CODATA, centra-se sobre a distribuição desses dados em uma rede colaborativa online. Além de ser um aplicativo para visualização de dados em dispositivos móveis, permite a construção de comunidades sociais em rede pela interação via comentários dos dados disponibilizados, bem como pela possibilidade de postagem de novos dados. O aplicativo tem como público-alvo o Ensino Médio Inovador, e pode ser aplicado em diferentes disciplinas, uma vez que pretende-se uma interação interdisciplinar entre alunos, professores e comunidade local e global no desenvolvimento do conhecimento visando à colaboração e cooperação.

O aplicativo CODATA tem referencias nas pesquisas de mestrado do Programa de Pós-Graduação em Tecnologias Educacionais em Rede, como a pesquisa "Dispositivos Móveis no Ensino Médio Inovador", de Lissandra Boessio sob orientação da Profa. Dra. Andreia Oliveira; bem como nas pesquisas do Programa de Pós-Graduação em Artes Visuais na linha Arte e Tecnologia, como a pesquisa "Narrativas Digitais em Rede" de Tatiana Guerche, sob orientação da Profa. Dra. Andreia Oliveira. Este projeto do CODATA parte da necessidade de pensarmos em uma nova metodologia de trabalho no Ensino Médio Inovador que dê conta de necessidades pedagógicas voltadas para o uso das tecnologias em rede. Estimulado pela distribuição de Tablets pelo governo federal, para os professores do ensino médio, iniciaram questionamentos sobre as possibilidades de utilização desses dispositivos móveis para potencializar aprendizagens diferenciadas nessa etapa da Educação Básica.

Contamos como base metodológica a Cartografia de Controvérsias, proposta por Bruno Latour, a qual é desenvolvida através da observação e descrição dos fenômenos que ocorrem ao longo dos agenciamentos entre humanos e não humanos. Deste modo, o CODATA direciona-se ao Ensino Médio Inovador que tem apresentado diversos desafios desde sua implementação, dentre eles, salientamos a integração curricular via propostas interdisciplinares e metodologias que vêm ao encontro de sistemas comunicativos abertos, proporcionando interação e colaboração. Apontamos que entre as políticas públicas que dão suporte ao Ensino Médio Inovador destaca-se o Pacto Nacional do Ensino Médio como uma política que visa capacitar os professores para que esses encontrem os subsídios necessários para sua prática voltada para os redesenhos curriculares e orientações vigentes, em especial, o Macrocampo Comunicação, Cultura Digital e Uso de Mídias que vem ao encontro das necessidades desses novos alunos imersos no mundo tecnológico. 


\section{Desenvolvimento}

No desenvolvimento do CODATA, realizamos prioritariamente quatro etapas separadas: a concepção pedagógica e conceitual, o design de interface do aplicativo, a programação do servidor e a programação do banco de dados.

Na elaboração da concepção pedagógica e conceitual, levamos em consideração desafios para um ensino interdisciplinar integrador, foco inicial de pesquisa com alunos do Ensino Médio Inovador, que segundo Azevedo (2013), são alunos que possuem visão de mundo e projetos de vida cuja constituição é produto de suas vivências sociais e educacionais. Como proposta, o CODATA apresenta-se como potencializador nesta mediação de vivências e saberes, em processos colaborativos. Observamos que faz-se necessário os alunos disponibilizarem suas produções para que sejam compartilhadas em rede gerando conhecimento coletivo e potencializando experiências significativas. Essas novas redes fazem com que a interação gere conhecimento, permitindo, assim, rever e reformular os processos de ensinoaprendizagem. A série de interconexões muda as relações, ampliando e modificando as ações, especialmente se os recursos aplicados forem utilizados de forma a potencializar o aprendizado através da visualização e interação a partir dos comentários postados no aplicativo. Assim, Primo (2011, p. 54) propõe "a valorização da complexidade dialógica do processo", os avanços oferecidos pela interação computacional, que ultrapassam barreiras geográficas e potencializam o diálogo. Este autor defende que o conceito de interatividade inclua as interações de forma horizontal e entre individuais.

Ainda, questiona-se as narrativas audiovisuais produzidas em rede, pois evidencia-se que o ato de compartilhar-las possibilita ao usuário uma troca de informações e interação social, fazendo com que o mesmo passe a obter conhecimento e, assim, aguçar a imaginação do usuário no desenvolvimento das mesmas. Além disso, Junior, Lisboa e Coutinho (2012) sugerem que os recursos tecnológicos devem ser utilizados de forma a possibilitar criatividade e reflexão e enfatizam que as narrativas digitais são materiais adequados a ser explorados em qualquer contexto de ensino-aprendizagem, com compartilhamento social e crítico. Dessa forma, Kieling (2012) menciona que o receptor de narrativas passa a não ser somente um sujeito que absorve informações, mas sim, que devido a evolução das tecnologias de informação e comunicação, passa a ser produtor e colaborador nas narrativas. De agente passivo, o indivíduo passa a sujeito atuante-participativo, possibilitando que o mesmo também seja autor do produto final.

Sobre o design de interface do aplicativo, priorizamos os processos de interatividade que o mesmo pode oferecer, bem como uma construção visual que propicie um acesso mais intuitivo e uma interface mais amigável. Os códigos e softwares que estão sendo utilizados são JAVA, XML, e netbeans. O ícone criado para o aplicativo CODATA a ser disponibilizado no Google Apps tem a imagem da rede como referência (Figura 1).

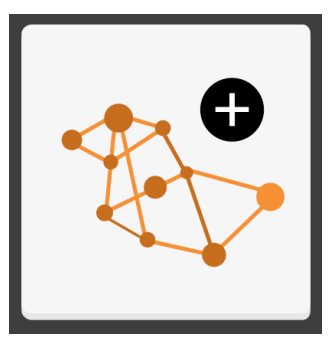


Figura 1. Ícone do aplicativo CODATA para dispositivos móveis

O primeiro estudo de design de interface da tela inicial priorizou uma interface com ênfase na construção visual e interativa (Figura 2).

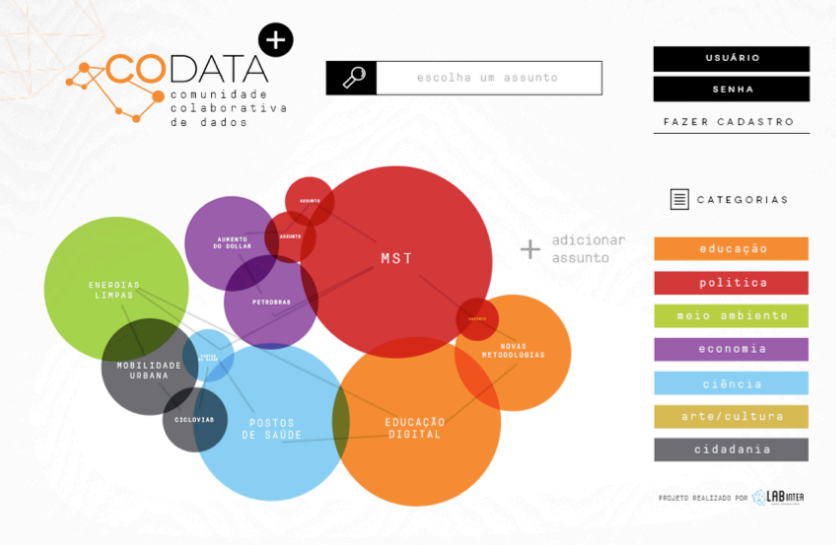

Figura 2. Estudo de Design de Interface da Tela Inicial

$\mathrm{Na}$ logomarca do CODATA utilizamos a imagem de rede e o próprio nome do aplicativo na construção visual (Figura 3).

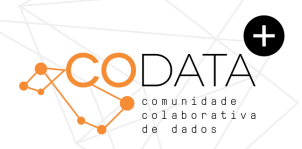

\section{Figura 3. Logomarca do aplicativo CODATA}

$\mathrm{Na}$ etapa de programação, o aplicativo foi desenvolvido visando dispositivos com sistema operacional Android que, por ser um sistema em ampla expansão e com grande diversidade de dispositivos suportados, por ser um sistema de código aberto e em amplo crescimento quanto a utilização e aceitação em novos dispositivos tem grande abrangência. $\mathrm{O}$ aplicativo foi desenvolvido na linguagem nativa Java, com uma interface em Javascript para a visualização gráfica das postagens. $\mathrm{O}$ design do aplicativo tenta seguir o novo guia de orientações para Android do Google, chamado de "Material Design". Neste são descritos as melhores recomendações para um visual atrativo e de fácil adaptação e uso por parte do usuário. O servidor foi escrito na linguagem de programação Java, devido a sua grande compatibilidade e versatibilidade, utilizando técnicas de comunicação via protocolo TCP/IP. Este servidor é responsável por efetuar a comunicação entre todos os aplicativos clientes, validar as requisições e informações que serão geradas ou recuperadas do banco de dados. Ainda não houve nenhum tipo de teste ou validação. 
CBIE-LACLO 2015

Anais dos Workshops do IV Congresso Brasileiro de Informática na Educação (CBIE 2015)

\section{Apresentação do Software}

O aplicativo móvel têm como principais características a visualização e a interação sobre as postagens. Logo na tela inicial, tem-se uma visão geral das postagens com mais contribuições. Elas estão divididas dentro de suas categorias e ligadas entre si por palavras-chave que o usuário cria e define (Figura 4). Através do menu lateral pode-se navegar pelas diferentes categorias, o que causa o filtro das postagens visualizadas para mostrar somente aquela categoria. Para se ter uma melhor experiência da utilização do aplicativo, é disponibilizado um vídeo demonstrativo que mostra a tela inicial e a navegação pelas categorias (https://vimeo.com/132153486).

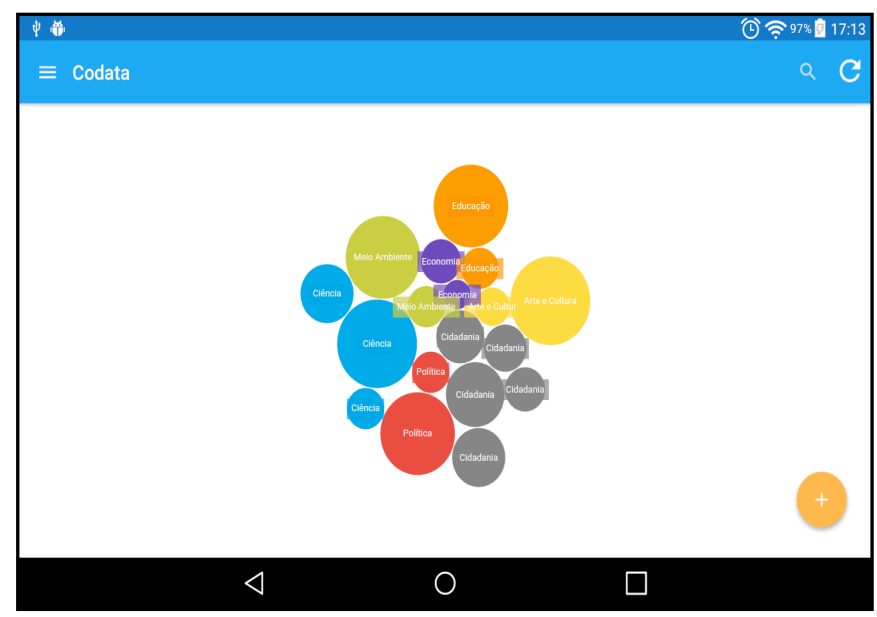

Figura 4. Tela inicial do aplicativo CODATA em desenvolvimento

A partir de qualquer menu de uma categoria, pode-se criar uma nova postagem. Ao clicar no botão de criação no canto inferior direito, abre-se uma nova tela aonde o usuário preenche os dados da postagem e pode incluir uma imagem e um vídeo relacionado (buscado diretamente no serviço do Youtube e Vimeo) para enriquecer a futura discussão. Por fim, as postagens criadas podem ser visualizadas por todos os usuários (Figura 5).

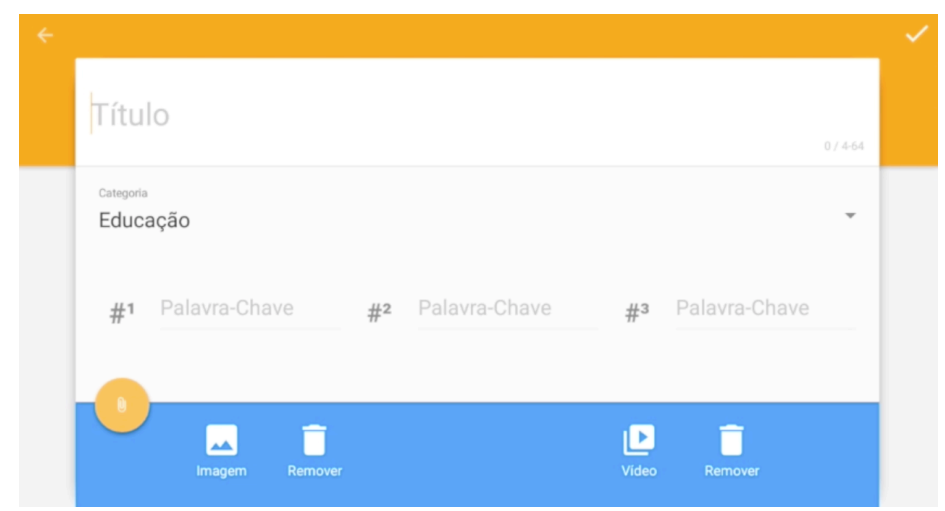

Figura 5. Tela de postagem do aplicativo CODATA em desenvolvimento 
CBIE-LACLO 2015

Anais dos Workshops do IV Congresso Brasileiro de Informática na Educação (CBIE 2015)

O usuário precisa se cadastrar para poder interagir no aplicativo, fazendo comentários ou postagens. Esta fase ainda encontra-se em estudo (Figura 6).

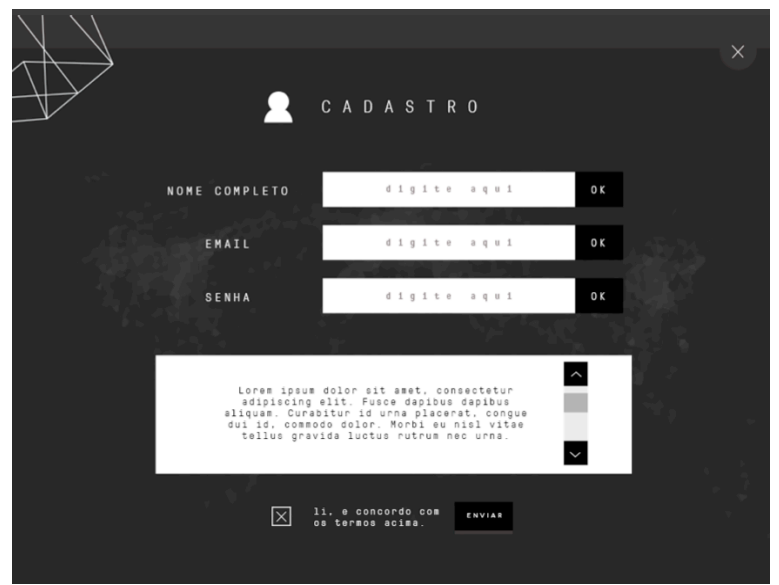

Figura 6. Tela de cadastro do aplicativo CODATA em desenvolvimento

Além dos dados enviados pelo usuário criador, há uma seção para comentários, destinada para conversa do tema por todos os interessados. Também é possível que outros usuários enviem mais imagens e vídeos para esta postagem, contribuindo para a discussão e expandindo a postagem. A Figura 7 mostra uma visualização geral desta tela e também pode-se ver a interação pelo vídeo nos detalhes da postagem.

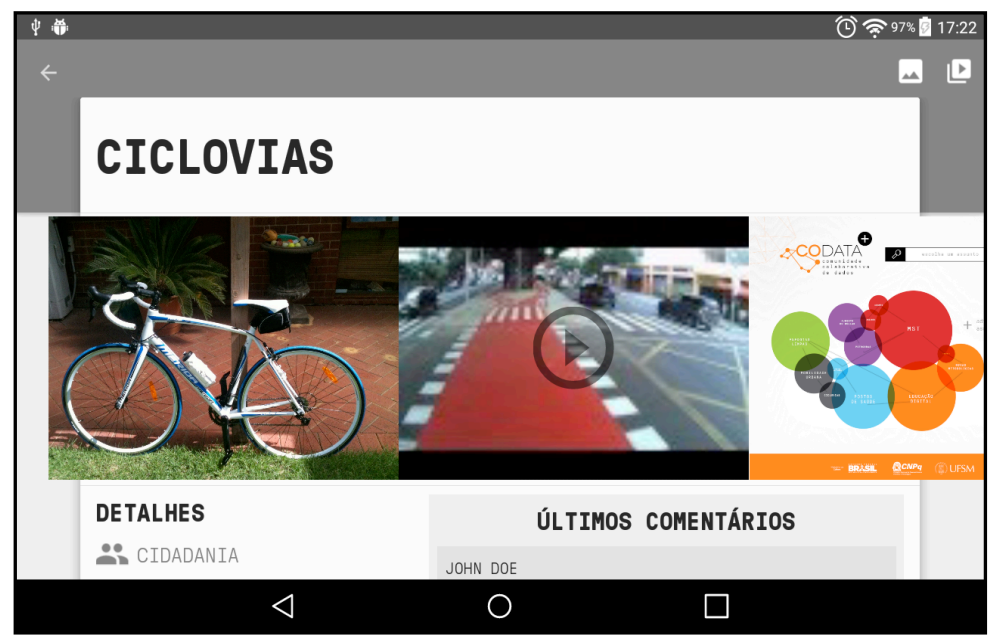

Figura 7. Tela de comentários do aplicativo CODATA em desenvolvimento

Tais informações sobre a apresentação do software podem ser encontradas com mais detalhes no vídeo demonstrativo com a licença de uso do mesmo.

\section{Considerações Finais}

O aplicativo CODATA investiga formas de consumir e distribuir dados através das tecnologias em rede de modo interativo e interdisciplinar. Nesse sentido é relevante destacar as estruturas de interface colaborativas, que surgem como espaços interativos não hierarquizados, que visam romper com linearidades onde a imagem do emissor se une com a do receptor. Em especial, com os dispositivos móveis, autor e co-autor 
produzem narrativas digitais em tempo real, podendo modificá-las a qualquer instante, refletindo assim sobre suas experiências e dos demais, não limitado a um círculo fechado e restrito. Portanto, reconhecemos que em uma produção colaborativa e cooperativa, as tecnologias em rede têm um papel fundamentalmente político, utilizada para uma prática contra a alienação tecnológica. Ao pensarmos na emancipação social em redes colaborativas, se produz comunidades de inovação composta por usuários que agem colaborativamente com os dados produzidos.

No que tange a aplicação do projeto serão realizados projetos iniciais em escolas de Ensino Médio Inovador na região sul do país, incluindo as seguintes cidades: Santa Maria, Cruz Alta e Santana do Livramento. Em Santana do Livramento, serão realizadas oficinas de produção de audiovisual em classe especial com alunos com deficiência visual, durante o período de Agosto a Dezembro de 2015, onde serão trabalhados os principais conceitos envolvidos na produção de vídeos e finalizando com a produção de narrativas digitais que serão compartilhadas no CODATA. Em Santa Maria e Cruz Alta já há materiais disponíveis para serem disponibilizados no aplicativo pelos alunos do Ensino Médio Inovador.

Como abordagem pedagógica, em conjunto com o Núcleo de tecnologia Educacional de Cruz Alta e escolas de Ensino Médio de abrangência da 9CRE, serão propostas oficinas pedagógicas referentes ao uso do aplicativo, aos professores que receberam Tablet a partir dos programas de políticas públicas de tecnologias nas escolas. Com objetivos de produzir conhecimento coletivamente e desenvolverem proposta em sala de aula que se utilizem do CODATA em diferentes abordagens pedagógicas, bem como que participem no processo como colaboradores com feedback a partir do desenvolvimento de atividades com seus alunos mediadas pelo CODATA. Assim, espera-se implementar o aplicativo CODATA nas escolas do Ensino Médio Inovador, inicialmente, para fins de avaliação, na região sul do país e, posteriormente, nas demais regiões.

\section{Referências}

Azevedo, J. C. e Reis, J. T. (2013) "O Ensino Médio e os desafios da experiência: movimento da prática". 1 ed. - São Paulo: Fundação Santillana: Moderna.

Junior, J. B. B., Lisboa, E. S., Coutinho, C. P. ( 2012) "Narrativas Digitais na Formação Inicial de Professores: Um Estudo com Alunos de Licenciatura em Pedagogia". Revista Teias. Rio de Janeiro, v. 13, n. 27. jan/abr. 2012.

Kieling, A. (2012) "Narrativas Digitais interativas e o uso da tecnologia como narrador implícito. Revista FAMECOS: mídia, cultura e tecnologia. Porto Alegre, v.19, n.3. set/dez. 2012.

Primo, A. (2011) "Interação mediada por computador: comunicação, cibercultura, cognição". 3. ed. Porto Alegre: Sulina. 